\title{
Caracterización de refractarios monolíticos
}

\author{
C. MARCOS ${ }^{1}$, M. A. LLORCA ${ }^{2}$, P. CAMBLOR ${ }^{3}$, L. F. VERDEJA ${ }^{4}$ \\ ${ }^{1}$ Dpto. Geología e Instituto de Química de Organometálicos "Enrique Moles", Univ. Oviedo, 33005 Oviedo \\ ${ }^{2}$ Dpto. Química Física y Analítica, Univ. Oviedo, 33006 Oviedo \\ ${ }^{3}$ Dpto. Estadística, Univ. Oviedo, 33007 Oviedo. \\ ${ }^{4}$ Dpto. Ciencias de los Materiales y Metalurgia, Univ. Oviedo, 3300 Oviedo
}

En este trabajo se han caracterizado mineralógica y texturalmente tres refractarios monolíticos bajo diferentes condiciones de calentamiento -sinterización, con el objeto de conocer su evolución. La caracterización mineralógica se ha realizado con difracción de rayos X, microscopia óptica y microsonda electrónica. La caracterización textural se ha llevado a cabo mediante el análisis con proceso de imágenes porque, para este tipo de refractarios, proporciona información de los poros y del disperso, no es una técnica destructiva y se pueden procesar imágenes con una resolución superior, en función de la óptica utilizada. Estas características diferencian el análisis con proceso de imágenes del porosímetro, técnica rutinaria muy utilizada para obtener de forma rápida el tamaño (entre 100 y $0.001 \mu \mathrm{m}$ ) y distribución de los poros en este tipo de materiales.

Palabras clave: Refractarios monoliticos, difracción de rayos X, microsonda electrónica, microscopia óptica, proceso de imágenes.

\section{Monolithic refractories characterization}

In this work three monolithic refractories with different thermal conditions -sintering have been characterized mineralogical and texturally in order to know its behaviour. The mineralogical characterization has been made by X-ray diffraction, optic microscopy and electron microprobe. The textural characterization was carried out by image analysis because, for this material type, it provides information about pores and dispersed material, the technique is not destructive and its resolution depends on the used optic. These characteristics distinguish between image process and porosimetry, routine technique used to obtain quickly the size (between 100 and $0.001 \mathrm{~mm}$ ) and pore distribution in this material type.

Keywords: monolithic refractories, X ray diffraction, electron microprobe, optic microscopy, image analysis.a

\section{INTRODUCCIÓN}

Los refractarios monolíticos, no conformados, moldeables $\mathrm{u}$ hormigones refractarios, han experimentado un vertiginoso crecimiento a lo largo de los últimos veinte años. En la actualidad constituyen más del 30\% de la producción mundial total de refractarios. Las causas de esta rápida expansión hay que buscarlas en la mayor facilidad y versatilidad de instalación, el amplio rango de temperaturas de empleo, así como en la capacidad de adaptarse a amplias variaciones en la composición química, mineralógica y granulométrica.

La composición de un refractario moldeable depende de su uso final pero están siempre presentes los óxidos de $\mathrm{Al}_{2} \mathrm{O}_{3^{\prime}} \mathrm{CaO}$ y $\mathrm{SiO}_{2}$, en mayor o menor proporción, además de impureza como $\mathrm{TiO}_{2}, \mathrm{Fe}_{2} \mathrm{O}_{3}, \mathrm{Cr}_{2} \mathrm{O}_{3}$ y otros aditivos que puedan modificar las propiedades físicas del refractario en función de sus aplicaciones. En los últimos años se han desarrollado asimismo una amplia gama de refractarios monolíticos de carácter básico.

Las propiedades mecánicas y físicas de estos materiales dependen del empaquetamiento de sus constituyentes. Por un lado, las características de resistencia, porosidad, densidad y estabilidad térmica vienen gobernadas por la compactación del refractario. Por otro lado, las cantidades de agua que necesita el refractario están directamente relacionadas con la distribución de tamaño de grano y con la matriz, es decir, depende de la porosidad de los agregados dispersos. Se pueden establecer así dos generalidades importantes:
1. Los agregados porosos de baja calidad requieren más cantidad de agua para rellenar los poros. Originan refractarios de elevada porosidad, baja densidad y menor resistencia.

Al mismo tiempo esta matriz, constituida por las fracciones granulométricas de menor tamaño de la composición, es la fase más reactiva y la que determina, por tanto, las propiedades químicas y de resistencia a la corrosión del conjunto del material.

2. Refractarios con contenido en cemento elevado requieren más cantidad de agua para alcanzar valores razonables de la resistencia mecánica del monolítico a temperatura ambiente antes de sinterizar. Esto implica aumento de la porosidad y disminución de la densidad en el producto resultante del tratamiento a elevadas temperaturas.

El objetivo principal que se persigue en la fabricación de estos materiales, para una composición dada, radica en obtener el máximo empaquetamiento con la menor cantidad de agua. Las propiedades de los refractarios moldeables están gobernadas, por lo tanto, por el tipo de agregado y matriz, así como por la cantidad de cemento usado. Estas variables gobiernan la cantidad de agua requerida y la microestructura que pueda adoptar el material resultante de la sinterización. Por otra parte, desde una óptica termo-mecánica, el constituyente matriz es responsable de la transmisión de los esfuerzos externos a la totalidad del material (agregados dispersos y poros). Por esta causa, las características del monolítico vienen determinadas en gran medida por las propiedades atribuidas al constituyente matriz. 
El objetivo de este trabajo es realizar una caracterización mineralógica y textural de refractarios moldeables en diferentes condiciones de calentamiento, para conocer su evolución con los ciclos térmicos y establecer la variación de la porosidad con las mismas. La determinación del constituyente matriz de un refractario sometido al contacto de un fluido corrosivo es importante por la intervención del denominado factor estructural presente en las ecuaciones de corrosión, consecuencia de la aplicación del Modelo de Desgaste Nodal al desgaste químico que controla la erosión del material. Normalmente, la ecuación nodal que expresa la velocidad de corrosión en la interfase refractario-fluído es inversamente proporcional a la proporción del constituyente matriz del refractario (Verdeja et al., 2000).

Finalmente, el trabajo quiere contribuir a significar la importancia de la textura sobre las propiedades de los materiales en general y de los monolíticos en particular con el propósito de desarrollar futuras normas de calidad que, además de contemplar las características químicas, físicas y mecánicas, incorporen criterios microestructurales.

\section{MATERIALES}

Los materiales estudiados en este trabajo se han denominado R1, R2 y R3. Las muestras R1 y R3, son características del material monolítico utilizado en revestimientos que contactan con arrabio, mientras que la R2 es un producto que se ha desarrollado para resistir las interacciones agresivas del acero líquido o las ferro-aleacciones. La composición elemental de estas muestras se presenta en la Tabla I.

También se han estudiado muestras refractarias sometidas a ciclos térmicos de calentamiento-enfriamiento con diferentes tiempos y temperaturas, es decir, han estado expuestas a procesos de sinterización cíclica, excepto R3 (material con características propias de las denominadas cerámicas estructurales). En la muestra R3 nos encontramos ante un producto que ha alcanzado cotas de densificación equivalentes a la de los materiales originales. En la Tabla II se muestra el número de ciclos térmicos, la temperatura y el tiempo empleado en cada una las de las muestras estudiadas, en condiciones ambientales oxidante (aire).

El aspecto de los monolíticos sin tratar térmicamente es muy diferente. Los refractarios R1 se presentan en bloques constituidos por una matriz microgranulada y un disperso (grano cuyo tamaño se diferencia a simple vista o con 50 aumentos) constituido básicamente por dos componentes con diferentes tamaños y colores. Como se verá más adelante, uno de los componentes es $\mathrm{Al}_{2} \mathrm{O}_{3}$ (corindón), de color blanco, aunque a veces con tonalidad rosa (debido al $\mathrm{Cr}^{3+}$ que entra como impureza sustituyendo al $\mathrm{Al}^{3+}$ ) o azul (por el $\mathrm{Fe}^{2+}$ y $\mathrm{Ti}^{4+}$ que sustituyen al $\mathrm{Al}^{3+}$ ). El otro componente es el CSi (moissanita) de color negro y aspecto metálico muy brillante.

Con el tratamiento térmico la superficie externa del refractario adquiere una tonalidad verdosa debido al cambio de color con la temperatura que sufre el $\mathrm{Al}_{2} \mathrm{O}_{3}$ con impurezas de Cr, Fe y Ti.

En un corte transversal de las muestras de los refractarios R2 sin tratar (muestra R2(A)) y las sometidas a ciclos térmicos de calentamiento-enfriamiento (R2(B), R2(C) y R2(D) se aprecia una textura granulada de ligero color verdoso. Como se confirmará más adelante, esta muestra está constituida, en su mayor parte, por granos de periclasa $(\mathrm{MgO})$.

El refractario R3 es de color blanco y muy compacto; en él
TABLA I.- COMPOSICIÓN QUÍMICA ELEMENTAL DE LOS REFRACTARIOS ESTUDIADOS

\begin{tabular}{cl}
\hline MUESTRA & \multicolumn{1}{c}{ COMPOSICIÓN (\%) } \\
\hline & $\mathrm{Al}_{2} \mathrm{O}_{3}=80$ \\
& $\mathrm{CSi}=10$ \\
R1 & $\mathrm{SiO}_{2}=5$ \\
& $\mathrm{C}=3$ \\
& $\mathrm{CaO}<1$ \\
\hline \multirow{4}{*}{ R2 } & $\mathrm{MgO}=75$ \\
& $\mathrm{CaO}=20$ \\
& $\mathrm{SiO}_{2}=0.6$ \\
& $\mathrm{Fe}_{2} \mathrm{O}_{3}=3.8$ \\
\hline \multirow{2}{*}{ R3 } & $\mathrm{Al}_{2} \mathrm{O}_{3}=98$ \\
& $\mathrm{SiO}_{2}=2$ \\
\hline
\end{tabular}

TABLA II.- CARACTERÍSTICAS DE LOS TRATAMIENTOS TÉRMICOS EFECTUADOS

\begin{tabular}{ccc}
\hline MUESTRA & $\begin{array}{c}\text { CICLOS } \\
\text { TÉRMICOS }\end{array}$ & TEMPERATURA/ TIEMPO \\
\hline R1(0) & 0 & - \\
R1(15) & 15 & $1400^{\circ} \mathrm{C} / 2$ horas a $7^{\circ} \mathrm{C} / \mathrm{min}$ \\
R1(30) & 30 & $1400^{\circ} \mathrm{C} / 2$ horas a $7^{\circ} \mathrm{C} / \mathrm{min}$ \\
\hline R2(A) & - & - \\
R2(B) & 1 & $1100^{\circ} \mathrm{C}$ a $7^{\circ} \mathrm{C} / \mathrm{min}$ \\
R2(C) & 8 & $1250^{\circ} \mathrm{C}$ a ${ }^{\circ} \mathrm{C} / \mathrm{min}$ \\
R2(D) & 1 & $1400^{\circ} \mathrm{C}$ a ${ }^{\circ} \mathrm{C} / \mathrm{min}$ \\
\hline R3 & - & - \\
\hline
\end{tabular}

no se puede distinguir material disperso debido a que la materia prima utilizada es muy homogénea y de pequeño tamaño, con deficiente ordenamiento cristalino y de alta reactividad sin presencia de fases fundidas.

\section{EXPERIMENTAL}

\subsection{Caracterización mineralógica}

La caracterización mineralógica de los refractarios es importante ya que constituye un paso previo para poder llevar a cabo el análisis textural mediante proceso de imágenes y estudiar su evolución con los ciclos térmicos. Se ha realizado con tres técnicas diferentes: Difracción de rayos X, microsonda electrónica y microscopía óptica. Con la primera se han identificado las fases cristalinas presentes en los refractarios; con la segunda se ha podido conocer las fases cristalinas que componen el disperso y la matriz y el porcentaje en óxidos de los elementos o el porcentaje en elementos de las fases previamente identificadas en el disperso; finalmente, por microscopía óptica se ha podido observar el color y textura del disperso, imprescindible en el análisis de imágenes. 


\subsubsection{DIFRACCIÓN DE RAYOS X}

La difracción de rayos $\mathrm{X}$ mediante el método de polvo cristalino se ha llevado a cabo con un difractómetro Philips PW 1729-1710 de los Servicios Científico Técnicos de la Universidad de Oviedo. En las Figuras 1 a 3 se muestran los espectros registrados para las diferentes muestras.

Las reflexiones encontradas experimentalmente en la muestra R1(0) se ajustan perfectamente con las correspondientes a las fichas de la base de datos JCPDS-ICDD (1996): 10-173 del corindón (C); 29-1126, 22-1317 y 29-1131 de los politipos hexagonales $2 \mathrm{H}, 4 \mathrm{H}$ y $6 \mathrm{H}$, respectivamente, de la moissanita (M); 15-776 de la mullita $(\mathrm{Mu})$ y 29-86 y 25-21 de una fase tipo mullita. Las fases mullíticas son las que menos destacan. En la muestra R1(15) aparecen las mismas fases de corindón, moissanita y mullita y desaparece la fase tipo mullita que se corresponde con la de la ficha JCPDS 29-86. En la muestra R(30) aparecen las mismas fases de corindón y mullita, desaparece el politipo $2 \mathrm{H}$ de la moissanita y las fases mullíticas que se corresponde con la de la ficha JCPDS 29-86 y 25-21.

La formación de la fase mullítica ocurre por la reacción de la alúmina del moldeable con la sílice alrededor de $1300^{\circ} \mathrm{C}$ aproximadamente, y produce una red de agujas que hacen de esta textura micrográfica sea más resistente a altas temperaturas y a los cambios bruscos de temperatura.

En los refractarios R2 las reflexiones se corresponden con
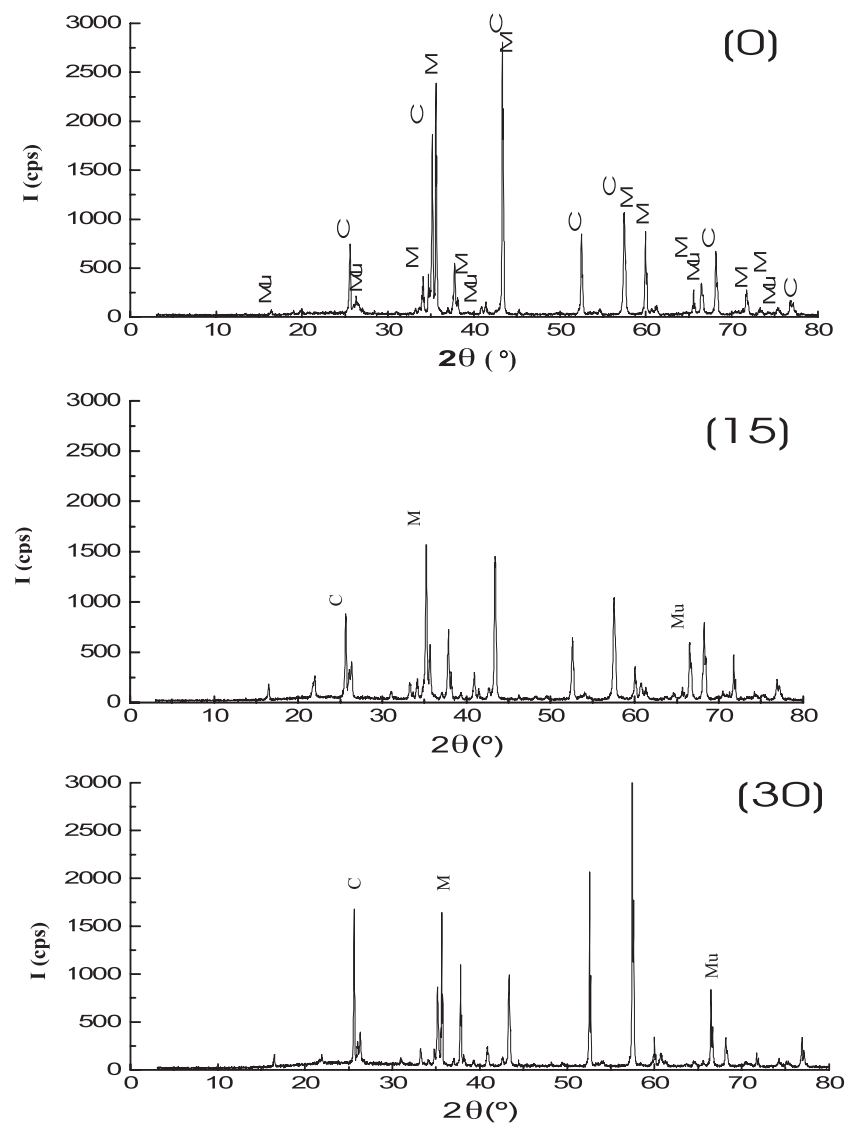

Figura 1.- Espectro de difracción de rayos $\mathrm{X}$ de las muestras $\mathrm{R} 1(0)$, R1(15) y R1(30) las de la periclasa (P), de acuerdo a la ficha 45-946 de la base de datos JCPDS-ICDD (1996), no observándose cambios con las distintas temperaturas de los tratamientos térmicos efectuados.

En el refractario R3, las reflexiones experimentales se ajustan perfectamente con las correspondientes a las fichas 10-173 del corindón $(\mathrm{C})$ y 15-776 de la mullita $(\mathrm{Mu})$, siendo estas dos fases las que se encuentran presentes en mayor proporción. También se ha detectado la presencia de óxido de silicio (Q) coincidente con la ficha 46-1045 que corresponde al cuarzo.

En los refractarios R1 se observa una disminución en las intensidades de las reflexiones de las fases presentes con los ciclos térmicos, comportamiento consistente con observaciones realizadas previamente por MacZura et al. (1985) que permiten explicar el aumento de la resistencia de los refractarios de bajo contenido en cemento con la temperatura.

\subsubsection{MICROSCOPÍA ÓPTICA}

Las observaciones ópticas de los refractarios se han realizado con un microscopio polarizante de reflexión en disposición ortoscópica sobre las superficies pulidas de los mismos, con el objeto de identificar cada componente del disperso. Para la obtención de las mismas se procedió a un proceso de montaje, desbaste y pulido de las muestras, siguiendo las recomendaciones descritas en Marcos y Moreiras (1984).

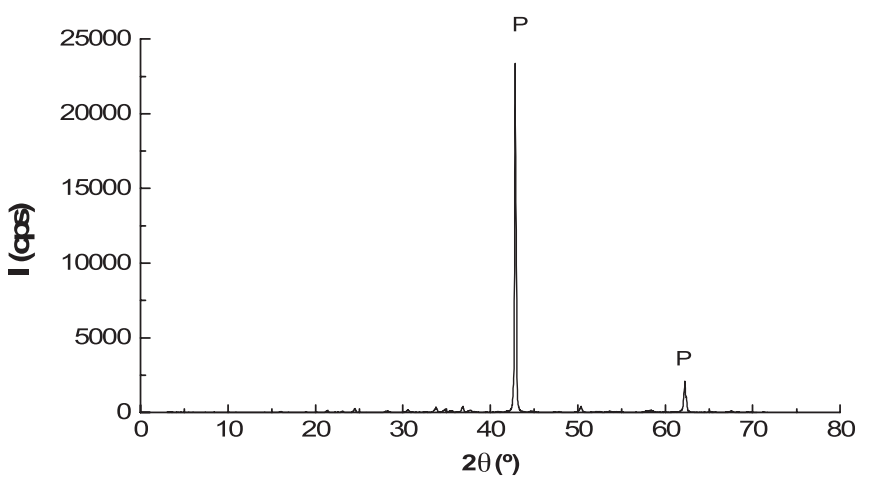

Figura 2.- Espectro de difracción de rayos X del monolítico R2(A)

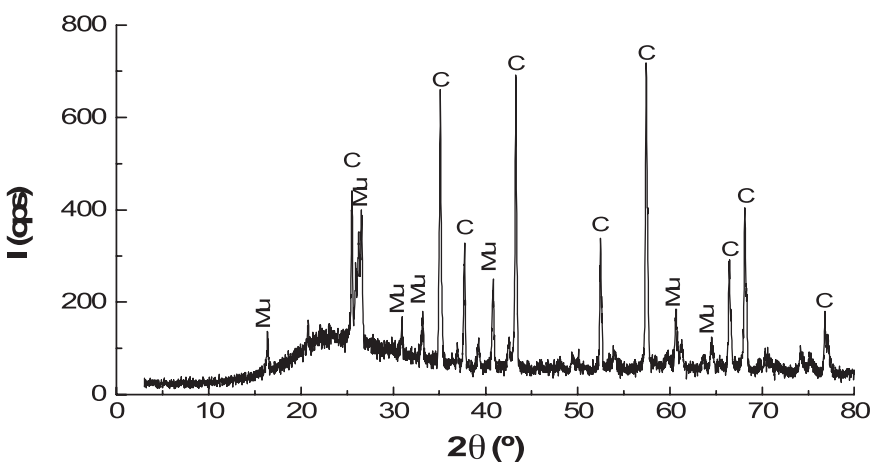

Figura 3.- Espectro de difracción de rayos X de la muestra R3. 
El refractario R1 sin tratar y el tratado con 15 ciclos térmicos presenta un disperso y una matriz en la que se pueden apreciar numerosos huecos o poros (Figura 4). El disperso lo constituyen granos diferentes en textura, forma, tamaño, color y reflectancia. Se distinguen dos fases minerales, una corresponde al CSi (moissanita hexagonal en su mayor parte) que se presenta como granos de color blanco, elevada reflectancia y pocos poros, de tamaño variable (Figura 4). La otra fase es $\mathrm{Al}_{2} \mathrm{O}_{3}$ (corindón) que presenta en reflexión color gris, menor reflectancia que el CSi, reflexiones internas (con polarizadores cruzados) y dos tipos de texturas. Hay unos granos que muestran numerosos poros de pequeño tamaño (Figura 5), mientras que otros presentan una superficie más homogénea pero con poros más grandes (Figura 6). Tanto en los granos de CSi como en los de $\mathrm{Al}_{2} \mathrm{O}_{3}$ se observan gran número de inclusiones pertenecientes a otras fases $(\mathrm{Si}, \mathrm{Ti}$ ) con color y reflectancia diferentes a la de los hospedantes, como se puede apreciar en la Figura 7.

En la muestra R1(30) (Figura 8) presenta un disperso en el que se aprecian claramente los granos de corindón y de moissanita, esta última en menor proporción que en las muestras anteriores, una matriz mullítica que incluye granos de corindón y poros, en proporción mayor que en las muestras anteriores.

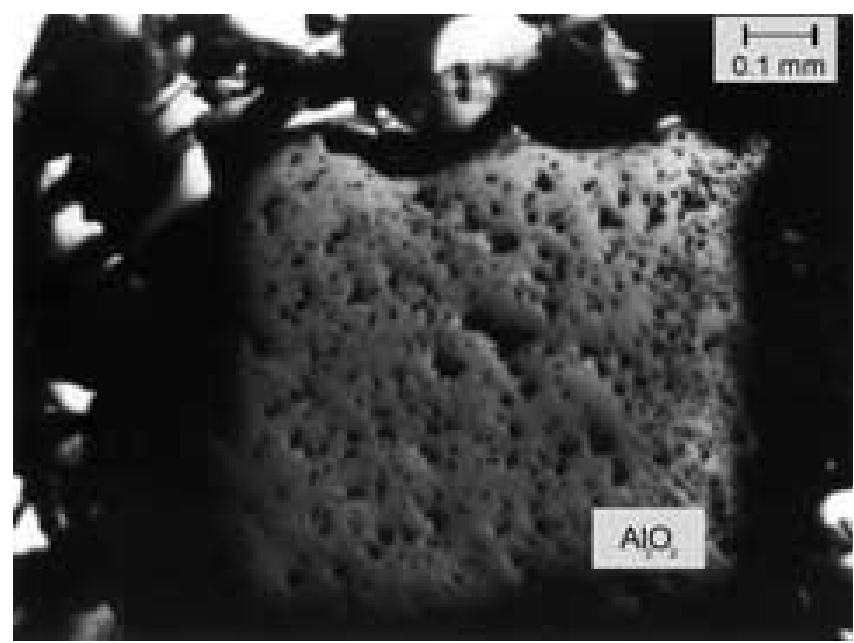

Figura 5.- Aspecto microscópico del corindón de los refractarios R1(0) y R1(15)

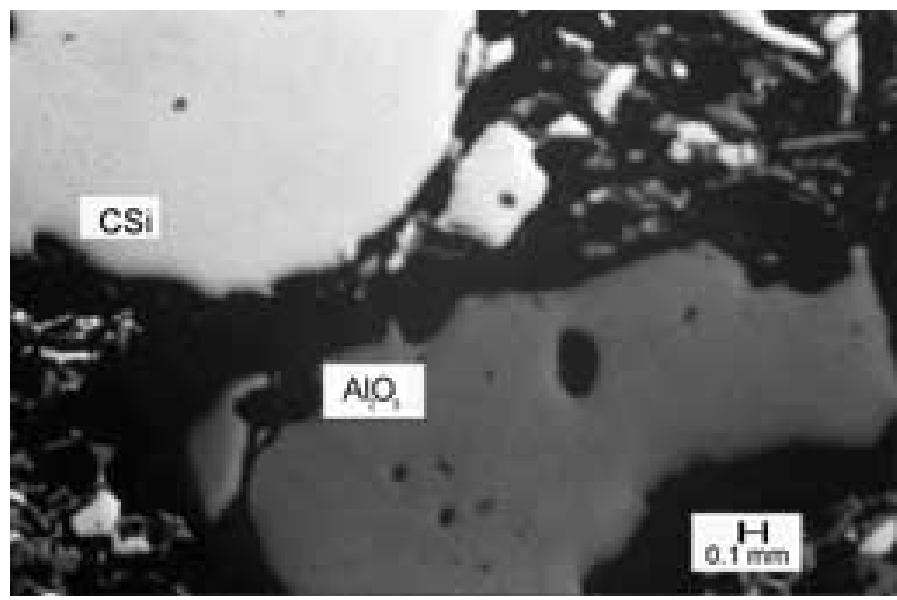

Figura 6.- Aspecto microscópico de otro grano de corindón presente en las muestras refractarias R1(0) y R1(15)

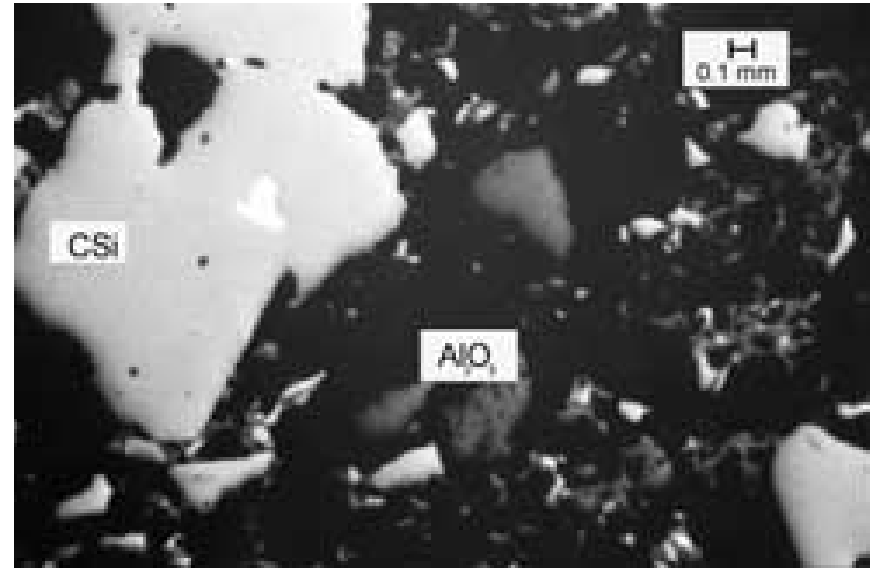

Figura 4.- Aspecto de la textura de los componentes de los refractarios correspondientes presentes en las muestras R1(0) y R1(15)

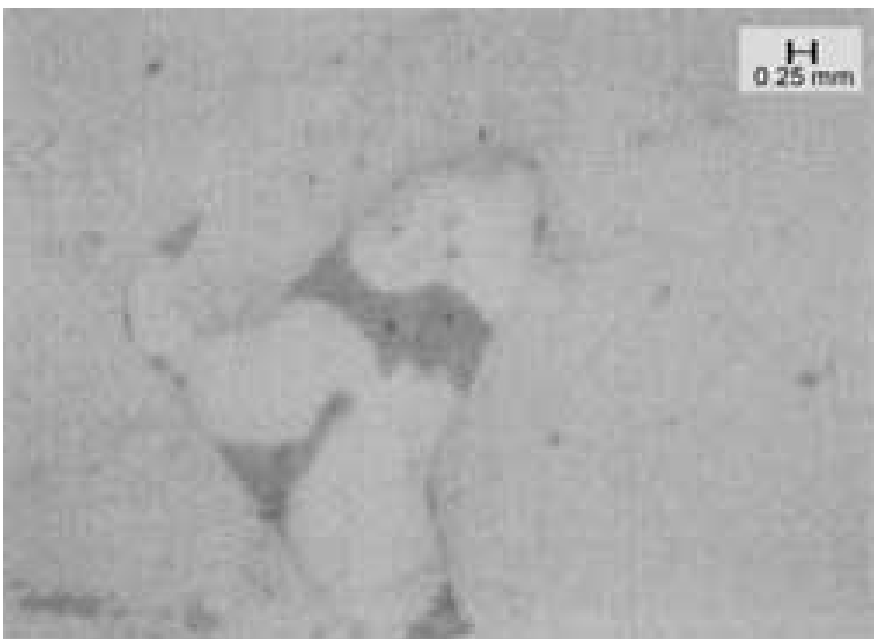

Figura 7.- Aspecto microscópico de las inclusiones de Si y Ti en el disperso de los refractarios R1(0) y R1(15)

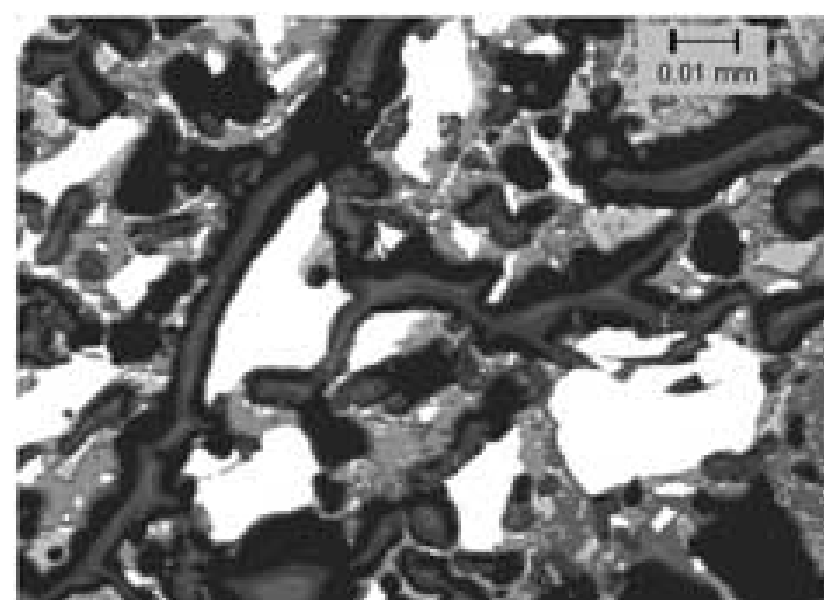

Figura 8.- Aspecto microscópico de los componentes del refractario R1(30) 


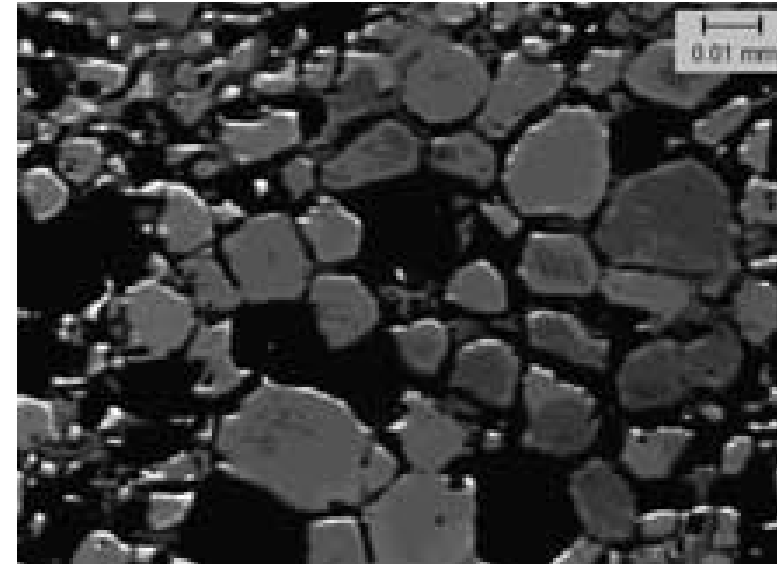

Figura 9.- Aspecto microscópico de materiales cuya composición química se identifica con R2

En el refractario R2 puede apreciarse que la matriz ocupa una proporción baja y es muy homogénea; los poros pueden distinguirse claramente y el disperso ocupa la mayor parte de la muestra (Figura 9). Está constituido por granos, que pertenecen a la misma fase mineral, prácticamente en contacto unos con otros, incoloros y con gran cantidad de reflexiones internas (denotando su transparencia), las formas son poligonales y apenas contienen poros. Cuando estas muestras se exponen al aire durante un tiempo se hidratan al pasar la periclasa a brucita (Figura 10).

El refractario R3 está constituido por fundamentalmente por matriz y poros. Su aspecto se muestra en la Figura 11, no pudiéndose apreciar claramente ningún constituyente primario disperso.

\subsubsection{MICROSONDA ELECTRÓNICA}

La microsonda electrónica ha permitido corroborar las fases cristalinas que constituyen el disperso y obtener la composición de las mismas. El equipo utilizado ha sido una CAMEBAX-MBX SX-50 de los Servicios Científico Técnicos de la Universidad de Oviedo.

Así, en los refractarios $\mathrm{R} 1$ se ha podido identificar como corindón $\left(\mathrm{Al}_{2} \mathrm{O}_{3}\right)$ los granos que en muestra de mano son transparentes y blancos (o de color azul o rosa), y en reflexión son grises poco reflectantes. También se ha corroborado que los granos que en reflexión son de color blanco y muy reflectantes corresponden al CSi (moissanita).

El promedio del porcentaje en peso de los elementos a partir de 5 análisis realizados sobre el corindón se muestra en la Tabla III. Puede comprobarse que dicho porcentaje coincide con el proporcionado en la bibliografía (p. ej. , Hurlbut y Klein, 1988) para esta fase $(\mathrm{Al}=52.9 \%$ y $\mathrm{O}=47.1 \%)$. El promedio del porcentaje en peso de los elementos a partir de 5 análisis realizados sobre moissanita de los refractarios R1 es el que se muestra en la Tabla IV. El cálculo del porcentaje en peso de los elementos constituyentes de la moissanita a partir de su fórmula, proporciona los valores siguientes: $29.15 \%$ para el C y $70.07 \%$ para el $\mathrm{Si}$, con los que existe buena correspondencia.

Los análisis realizados en 5 puntos del refractario R2 y cuyo promedio se presenta en la Tabla $\mathrm{V}$ corroboran que el componente mayoritario es la periclasa $(\mathrm{MgO})$. En la matriz de esta muestra también se han analizado cinco puntos, cuyo promedio se recoge en la Tabla $\mathrm{V}$, correspondientes a una fase silicatada matriz de calcio y magnesio.

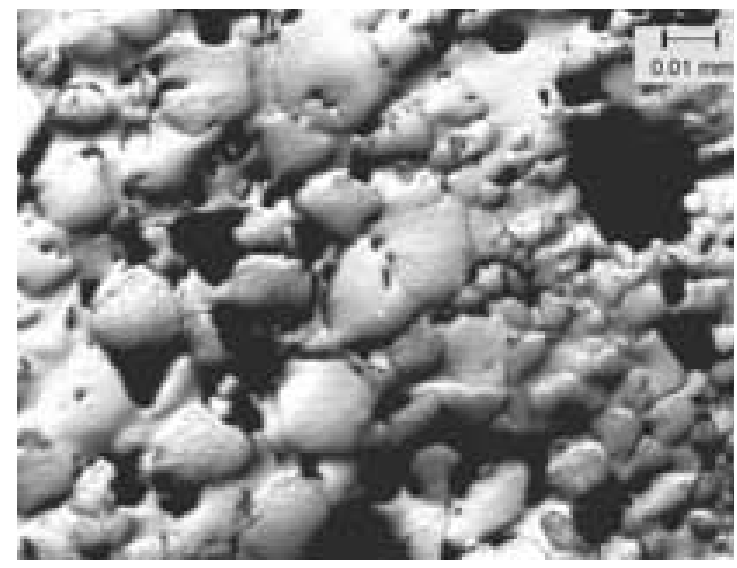

Figura 10.- Aspecto microscópico de la alteración de las muestras cuya composición química se identifican con el material R2.

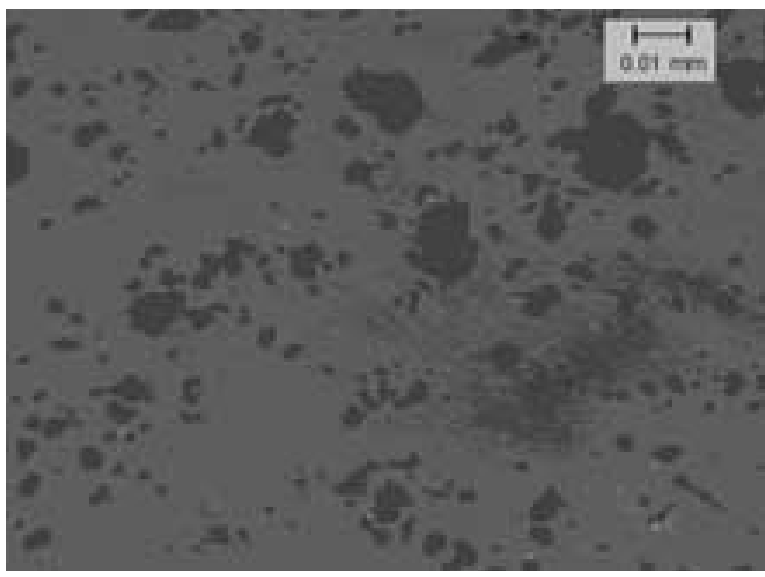

Figura 11.- Aspecto microscópico del refractario R3

\begin{tabular}{cr}
\hline Elemento & \multicolumn{1}{c}{$\mathrm{R} 1(0)$} \\
\hline $\mathrm{Si}$ & $0.039(0.033)$ \\
$\mathrm{Al}$ & $52.487(0.028)$ \\
$\mathrm{Ca}$ & $0.011(0.011)$ \\
$\mathrm{Ti}$ & $0.007(0.009)$ \\
$\mathrm{Fe}$ & $0.044(0.029)$ \\
$\mathrm{C}$ & $0.056(0.083)$ \\
$\mathrm{O}$ & $47.283(0.439)$ \\
\hline
\end{tabular}

TABLA III.- PORCENTAJE EN PESO DE LOS ELEMENTOS DEL CORINDÓN $\left(\mathrm{Al}_{2} \mathrm{O}_{3}\right)$ PARA LA MUESTRA $\mathrm{R} 1(0)$

\begin{tabular}{cr}
\hline Elemento & \multicolumn{1}{c}{$\mathrm{R} 1(0)$} \\
\hline $\mathrm{Si}$ & $68.229(0.838)$ \\
$\mathrm{Al}$ & $0.089(0.069)$ \\
$\mathrm{Ca}$ & $0.0080(0.006)$ \\
$\mathrm{Ti}$ & $0.006(0.005)$ \\
$\mathrm{Fe}$ & $0.014(0.026)$ \\
$\mathrm{C}$ & $31.650(0.870)$ \\
\hline
\end{tabular}

TABla IV.- Porcentaje EN PESO DE LOS ELEMENTOS DE MOISSANITA (CSi) EN LA MUESTRA R1(0)

TABla V.- Porcentaje EN PESO DE LOS ElEMENTOS PRESENTES EN EL DISPERSO DE PERICLASA (MgO) Y EN FASE SILICATADA DE Mg Y Ca DE LA MATRIZ DE LA MUESTRA R2(A)

\begin{tabular}{crr}
\hline Elemento & \multicolumn{1}{c}{ Disperso } & \multicolumn{1}{c}{ Matriz } \\
\hline $\mathrm{Na}$ & $0.002(0.003)$ & $0.006(0.004)$ \\
$\mathrm{K}$ & $0.007(0.005)$ & $0.005(0.004)$ \\
$\mathrm{Ca}$ & $0.021(0.060)$ & $18.704(0.618)$ \\
$\mathrm{Fe}$ & $0.250(0.070)$ & $0.056(0.042)$ \\
$\mathrm{Mg}$ & $58.267(0.207)$ & $17.978(0.597)$ \\
$\mathrm{Al}$ & $0.292(0.254)$ & $0.053(0.015)$ \\
$\mathrm{Si}$ & $0.007(0.005)$ & $18.541(0.243)$ \\
$\mathrm{O}$ & $38.694(0.200)$ & $40.488(0.406)$ \\
\hline
\end{tabular}


Los análisis de microsonda del refractario R3 muestran que las fases presentes en el mismo son silicatos alumínicos tipo mullita, Tabla VI, aunque también aparece algo de $\mathrm{Al}_{2} \mathrm{O}_{3}$ y $\mathrm{SiO}_{2}$.

\subsection{Caracterización textural}

Se ha llevado a cabo mediante el análisis con proceso de imágenes sobre las muestras identificadas por difracción de rayos $X$, microscopia óptica y microsonda electrónica, utilizando para ello el equipo de los Servicios Científico Técnicos de la Universidad de Oviedo.

Las técnicas de análisis de imagen guardan relación con las medidas de las características geométricas de las muestras que son expuestas como imágenes en dos dimensiones. Estas imágenes se analizan por métodos que proporcionan resultados cuantitativos completos. Con el analizador de imágenes QUANTIMET usado en este trabajo, la imagen observada a través del microscopio se registra en una pantalla de televisión. Esta imagen se subdivide en un gran número de pixeles y a cada uno se le asigna un valor que depende de su brillantez (nivel de grises). Los valores de nivel de grises se almacenan en el ordenador y se usan para hacer conjuntos de medidas. La resolución espacial que se puede alcanzar es de 4 o $5 \mu \mathrm{m}$.

En este estudio los parámetros utilizados para la caracterización textural han sido los siguientes: Área del disperso, de la matriz y de los poros; porcentaje del disperso, de la matriz y de los poros; diámetros máximo $(\mathrm{L}=$ longitud $)$ y mínimo $(\mathrm{B}$ = anchura) de los poros $\mathrm{y}$ factor de forma $(\mathrm{R}=$ redondez).

En la toma de las medidas mencionadas se tuvieron en cuenta las limitaciones operacionales y errores en el proceso de análisis de imágenes, en relación a la resolución espacial, identificación de los componentes de los refractarios y mal registro de los resultados (Jones, 1987).

Posteriormente, se pretendió inferir las características de los datos sobre el disperso, la matriz y los poros de los diferentes refractarios analizados, a partir de muestras de los mismos. Se ha tratado, en definitiva, de describir de forma clara y conveniente las características de un conjunto de datos, teniendo en cuenta que la distribución de los mismos no siempre responde a un modelo normal.

Después de haber realizado algunos análisis con el proceso de imágenes se planteó establecer el número de datos a medir y, por lo tanto, a considerar como fiables. Para ello se tuvieron en cuenta las siguientes consideraciones:

1. Se acepta que las muestras de refractarios estudiadas en este trabajo son representativas de los mismos.

2. El área analizada con el proceso de imágenes, de acuerdo a la preparación de la muestra requerida en el análisis, no ha sido superior a $2 \mathrm{~cm}^{2}$ en $\mathrm{R} 1$ y a $0,5 \mathrm{~cm}^{2}$ en los refractarios R2 y R3.

3. El área de cada uno de los campos donde se han llevado a cabo las medidas en el proceso de imágenes, en función de los aumentos utilizados con el microscopio, no ha sido superior a $1 \mathrm{~mm}^{2}$ en los refractarios $\mathrm{R} 1$ y a $0,5 \mathrm{~mm}^{2}$ en los refractarios $\mathrm{R} 2$ y $\mathrm{R} 3$.

4. El número máximo de campos explorados en el análisis con proceso de imágenes para obtener el porcentaje de disperso, matriz y poros es alrededor de 70 en los refractarios R1 y de 60-65 en los refractarios R2 y R3.

5. El número de medidas que pueden realizarse en los campos citados es muy elevado, dependiendo del número y tamaño del disperso diferenciado y de los poros.
TABLA VI.- ANÁLISIS QUíMICO ELEMENTAL EN CINCO PUNTOS DEL MATERIAL R3

\begin{tabular}{crrrrr}
\hline ÓXIDOS & \multicolumn{6}{c}{ PORCENTAJE EN PESO } \\
\hline \multicolumn{1}{c}{1} & \multicolumn{1}{c}{2} & \multicolumn{1}{c}{3} & \multicolumn{1}{c}{4} & \multicolumn{1}{c}{5} \\
\hline $\mathrm{SiO}_{2}$ & 67.250 & 43.613 & 58.832 & 48.465 & 28.263 \\
$\mathrm{Al}_{2} \mathrm{O}_{3}$ & 20.536 & 56.123 & 31.096 & 42.898 & 66.149 \\
$\mathrm{~K}_{2} \mathrm{O}$ & 6.916 & 3.076 & 5.478 & 3.941 & 3.021 \\
$\mathrm{Na}_{2} \mathrm{O}$ & 0.700 & 0.342 & 0.521 & 0.421 & 0.220 \\
$\mathrm{MgO}$ & 0.618 & 0.291 & 0.460 & 0.472 & 0.257 \\
$\mathrm{CaO}$ & 0.341 & 0.148 & 0.237 & 0.210 & 0.182 \\
$\mathrm{TiO}$ & 0.389 & 0.237 & 0.350 & 0.337 & 0.170 \\
$\mathrm{FeO}$ & 0.902 & 0.471 & 0.628 & 0.743 & 0.358 \\
$\mathrm{NiO}$ & 0.000 & 0.000 & 0.063 & 0.005 & 0.121 \\
$\mathrm{Cr}_{2} \mathrm{O}_{3}$ & 0.081 & 0.000 & 0.000 & 0.000 & 0.081 \\
$\mathrm{MnO}$ & 0.000 & 0.000 & 0.063 & 0.058 & 0.078 \\
\hline
\end{tabular}

El estudio estadístico inferido de los datos se ha llevado a cabo sobre las muestras R1, sin tratar y las tratadas con $15 \mathrm{y}$ 30 ciclos térmicos, y sobre las R2 sin tratar y las tratadas con 8 ciclos térmicos a diferentes temperaturas.

Para fijar el tamaño muestral mínimo, en cuanto a campos a considerar en el análisis con el proceso de imágenes se refiere, se ha determinado previamente la precisión y confianza deseadas y se ha observado el tipo de distribución de los datos correspondientes al porcentaje de matriz, poros y disperso. Las expresiones utilizadas son las siguientes:

$$
\mathbf{P}\{-\mathbf{a} \leq \overline{\mathbf{P}}-\mathbf{P} \leq \mathbf{a}\} \geq \mathbf{1}-\alpha
$$

donde: $P$ es la probabilidad; $a$ es la amplitud del intervalo; $\alpha$ es la confianza

En el caso de normalidad, el tamaño muestral vendrá dado por:

$$
\mathbf{n}=\left(\frac{\boldsymbol{z}_{\alpha} \sigma}{\boldsymbol{a}}\right)^{2}
$$

donde: $z_{\alpha}$ es el valor que verifica que $\mathrm{P}\left\{-z_{\alpha} \leq \mathrm{N}(0,1) \leq z_{\alpha}\right\} \geq 1-\alpha$ y vale 1.965 para una confianza del $95 \%$ y 2.57 para el $99 \%, \mathrm{n}$ es el tamaño muestral, $\sigma$ es la desviación típica

En el caso de no conocer la distribución de la variable aleatoria se puede utilizar la expresión:

$$
n=\frac{\sigma^{2}}{a^{2}}
$$

El valor de la desviación $\sigma$ se calculó con el programa informático SPSS (versión 9.0.1, 1989-1999).

En el caso de las muestras R1 sin tratar y las tratadas con 15 ciclos térmicos la distribución de los datos es muy variable y no se puede suponer normal, por lo que se utiliza la cota de Chevichev. Para una precisión del 10\% y una confianza del 95\%, se han obtenido los tamaños muestrales de la Tabla VII.

TABLA VII.- TAMAÑOS MUESTRALES PARA LOS MONOLíticos R1(0) Y R1(15)

\begin{tabular}{|l|r|r|l|r|r|r|}
\hline \multicolumn{1}{|c|}{ Muestra } & \multicolumn{2}{|c|}{$\mathrm{R} 1(0)$} & \multicolumn{3}{c|}{$\mathrm{R} 1(15)$} \\
\hline & media & $\sigma$ & $\mathrm{n}$ & Media & \multicolumn{1}{c|}{$\sigma$} & $\mathrm{n}$ \\
\hline \% matriz & 10,75 & 14,60 & 43 & 16,79 & 20,69 & 86 \\
\hline \% poros & 77,81 & 11,52 & 27 & 78,48 & 6,02 & 8 \\
\hline \% disperso & 11,44 & 9,93 & 20 & 4,73 & 18,09 & 66 \\
\hline
\end{tabular}


En el caso de las muestras R2 la distribución de los datos se puede suponer normal y para una precisión del $5 \%$ y una confianza del 95\%, se han obtenido los tamaños muestrales de la Tabla VIII.

Teniendo en cuenta estos resultados se considera como número de campos adecuados a analizar los siguientes: 70 en R1, 20 en R2 y R3.

\subsubsection{MUESTRAS TIPO R1}

\subsubsection{Análisis de los porcentajes de disperso, matriz y poros}

Para los refractarios R1, tanto para las muestras de partida como para las tratadas con 15 y 30 ciclos térmicos, se han efectuado, con el sistema de cálculo de área, las siguientes medidas: a) Porcentajes de poros, matriz y disperso; b) porcentajes de matriz y disperso, discriminando los componentes más reflectantes (moissanita) de los menos reflectantes (corindón); c) porcentajes de los poros en los componentes mayori-
TABLA VIII.- TAMAÑOS MUESTRALES PARA LOS PRODUCTOS R2(A), R2(B), R2(C) Y R2(D)

\begin{tabular}{|l|r|r|r|r|r|r|r|r|r|r|r|r|}
\hline Muestra & \multicolumn{3}{|c|}{ R2(A) } & \multicolumn{3}{c|}{ R2(B) } & \multicolumn{3}{c|}{ R2(C) } & \multicolumn{3}{c|}{ R2(D) } \\
\hline & media & $\sigma$ & $n$ & media & $\sigma$ & n & media & $\sigma$ & n & media & $\sigma$ & n \\
\hline \% matriz & 17,11 & 6,50 & 7 & 20.75 & 5,27 & 5 & 28,08 & 7,30 & 9 & 28,16 & 8,38 & 11 \\
\hline \% poros & 29,19 & 9,79 & 15 & 13,23 & 5,86 & 6 & 15,30 & 4,96 & 4 & 15,06 & 6,68 & 7 \\
\hline \% disperso & 53,70 & 10,69 & 18 & 66,02 & 7,87 & 10 & 56,62 & 8,55 & 12 & 56,78 & 9,53 & 15 \\
\hline
\end{tabular}

tarios inferiores a $1 \mathrm{~mm}^{2}$ de las muestras y sus características geométricas; d) características geométricas de los poros de los refractarios.

Los resultados de las medidas de los apartados a) y b) se muestran en las Figuras 12 a 14. Los intervalos de confianza son al 95\% suponiendo normalidad, aunque las distribuciones resultantes son en general asimétricas y los cálculos se han realizado con pruebas de Mann-Whitney para dos grupos y de Kruskall-Wallis para más de dos grupos (Wayne,1995).

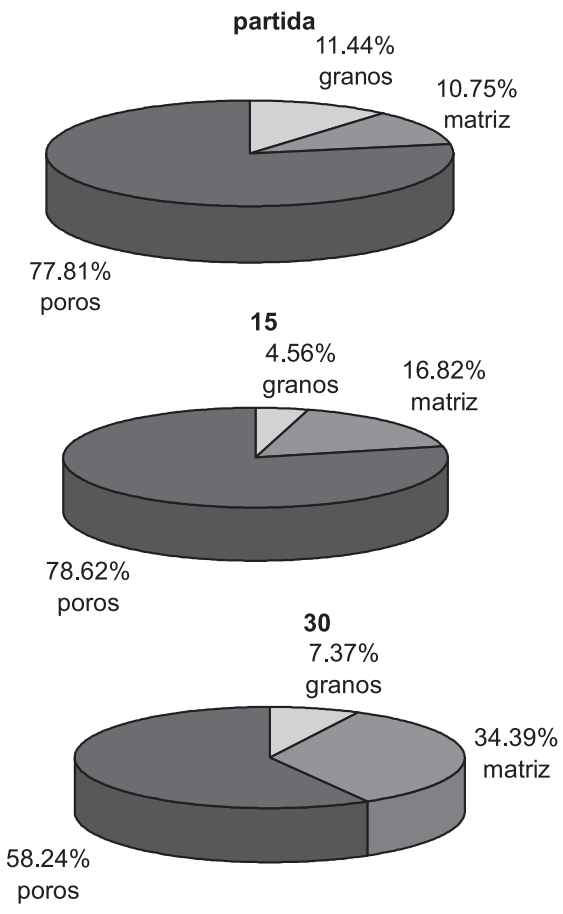

Figura 12.- Porcentajes de disperso, matriz y poros en muestras del tipo R1

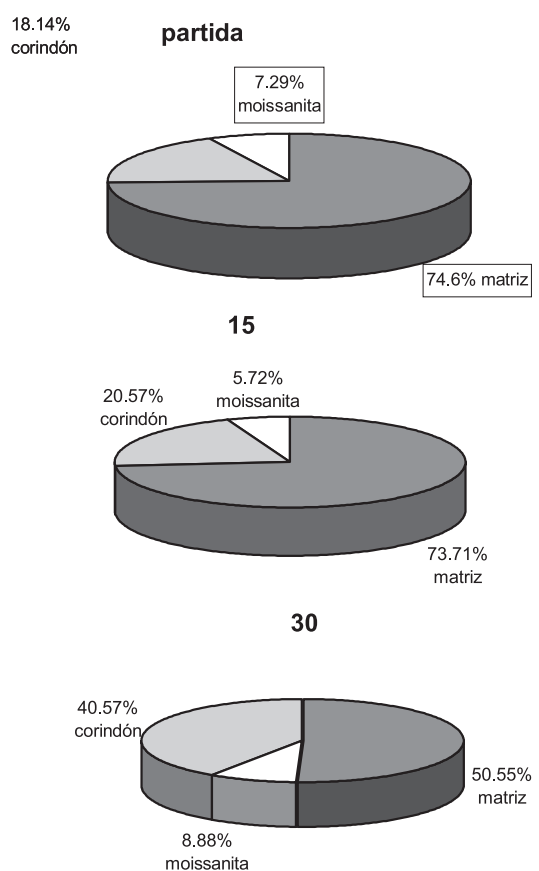

Figura 14.- Porcentajes de las fases minerales mayoritarias en los materiales tipo R1
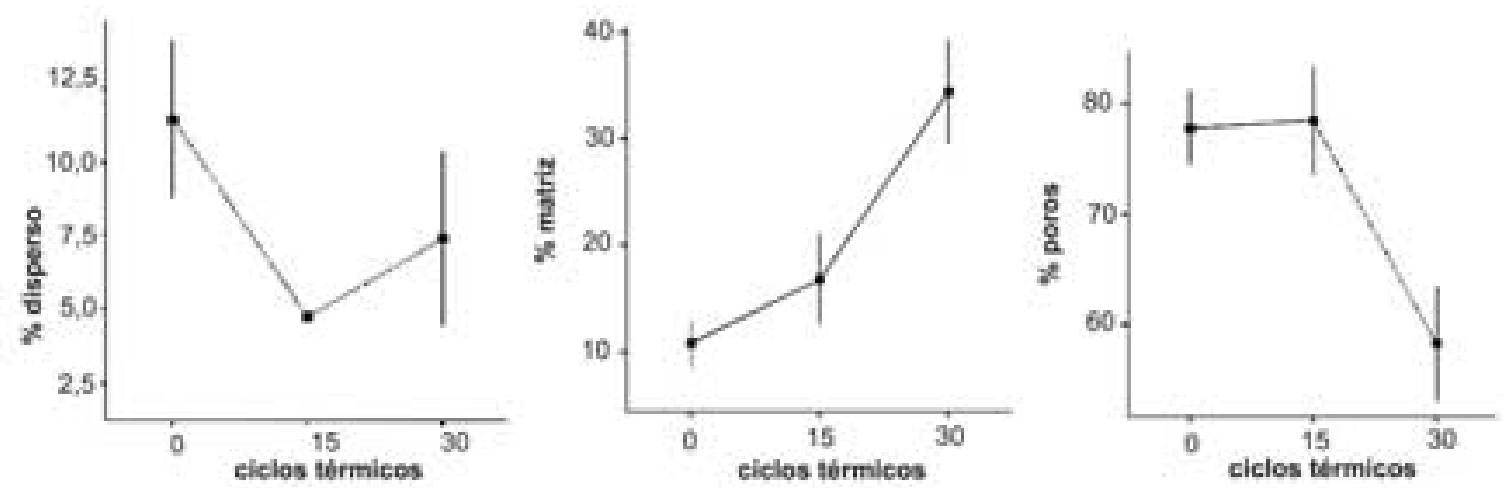

Figura 13.- Gráficos de evolución con los ciclos térmicos del disperso, la matriz y los poros de las muestras tipo R1 

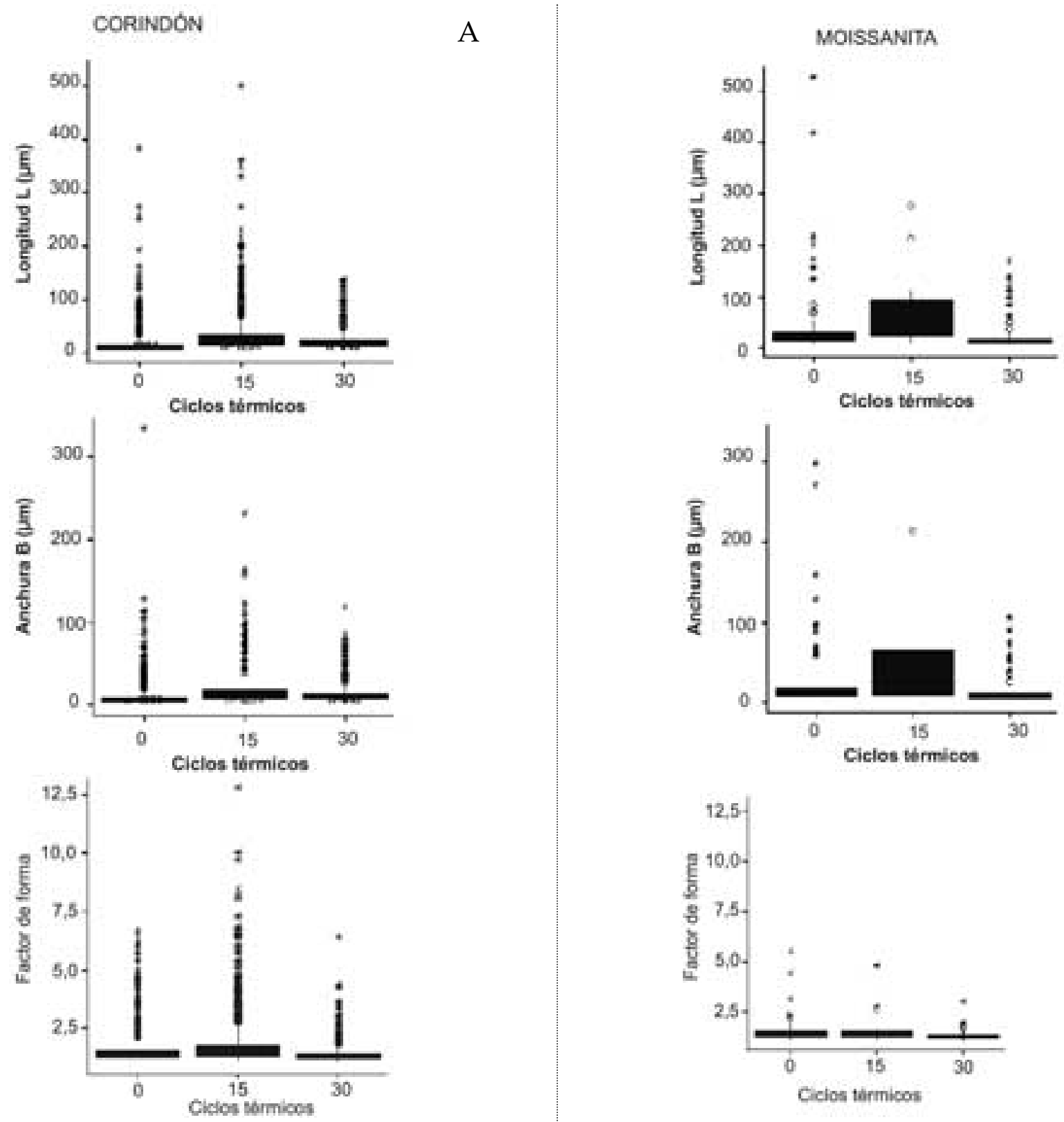

Figura 15.- Gráficos de evolución con los ciclos térmicos de las características geométricas de los poros en el disperso de las muestras tipo R1

De dichos resultados se pueden extraer las siguientes conclusiones:

1. Se observan diferencias significativas en las tres variables, con p-valores de 0.000 , entre el refractario sin tratar y el tratado con 30 ciclos. En la Figura 13 se aprecia claramente la disminución de la matriz y de los poros y el aumento del disperso con los 30 ciclos térmicos.

2. En relación al porcentaje de las fases minerales mayoritarias de estos refractarios (Figura 14):

- El corindón es el que está en mayor proporción y aumenta considerablemente en los materiales que han sido tratados con 30 ciclos térmicos.

- La moissanita está en una proporción bastante menor.

- El silicato de aluminio tipo mullita aparece formando la matriz.

3. La presencia y proporción de estas fases minerales es la que cabría esperar en función de la composición química ele- mental, Tabla I, y las reacciones que pudieran producirse. Un ejemplo es la fase silicatada tipo mullita, muy importante porque en los refractarios de este tipo les confiere resistencia a las altas temperaturas, que aparece como consecuencia de la fuerte reacción mullítica entre la alúmina $\left(\mathrm{Al}_{2} \mathrm{O}_{3}\right)$ y la sílice $\left(\mathrm{SiO}_{2}\right)$ a partir de $1300{ }^{\circ} \mathrm{C}$ (Seltveit, 1986).

En relación al apartado c), se puede decir que el porcentaje de poros dentro del disperso es inferior al 35\% en todos los casos, observándose una disminución en el número de ellos con 30 ciclos térmicos.

Las características geométricas de los poros presentes en los granos de disperso (corindón y moissanita) se presentan en la Figura 15. Los p-valores de las pruebas no paramétricas fueron iguales a 0.000 excepto en el aspect ratio. Analizando los resultados se deduce que los poros se hacen más redondeados al aumentar el número de ciclos térmicos y que los de mayor tamaño presentan formas más alargadas. 

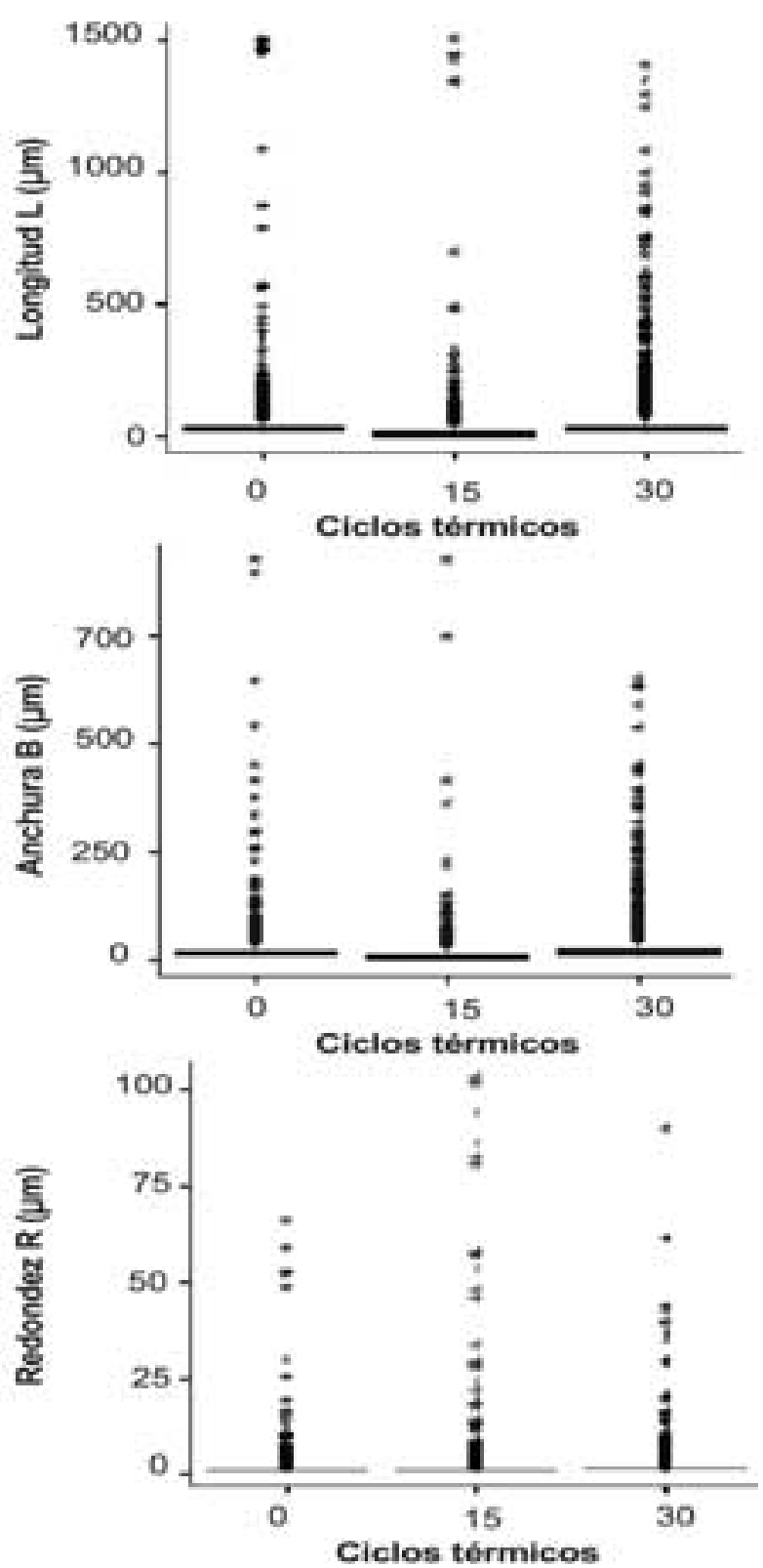

Figura 16.- Evolución con los ciclos térmicos de las características de geométricas de los poros dentro de los monolíticos tipo R1

En la Figura 16 se puede apreciar la evolución de las características de los poros en el refractario R1 con los ciclos térmicos. La mayoría de las variables son bastante asimétricas e incluso algunas claramente bimodales (área), por lo que se realizaron nuevamente pruebas no paramétricas. Analizando las diferencias se observó que eran significativas en todas las variables estudiadas ( $p$-valores de 0.000 ) salvo en la redondez (p-valor de 0.553). Y como en el caso de los poros dentro del disperso, los poros se hacen más alargados al aumentar los ciclos térmicos y originan fisuras en el material.

\subsubsection{MUESTRAS TIPO R2}

Para las muestras de estos refractarios se han efectuado, con el sistema de medida de área, las siguientes medidas: a) Porcentajes de poros, matriz y disperso; b) características geo-

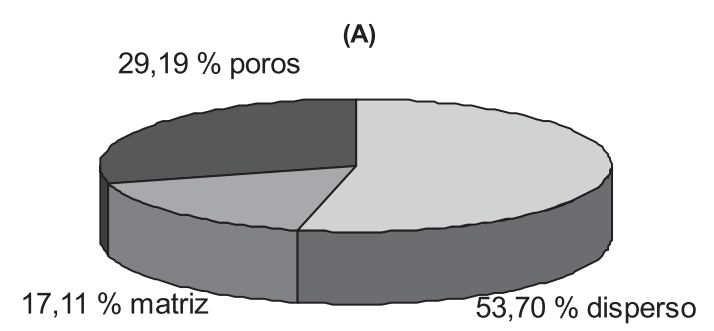

(B)

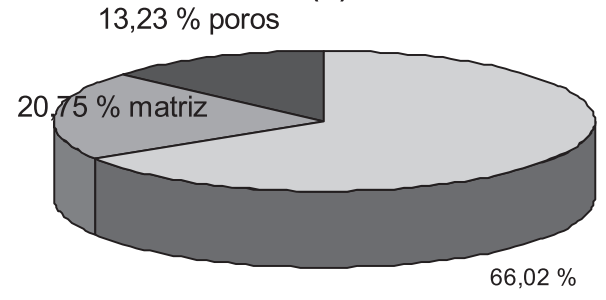

(C)

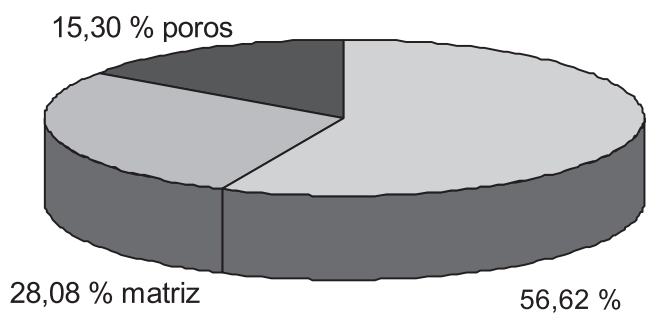

(D)

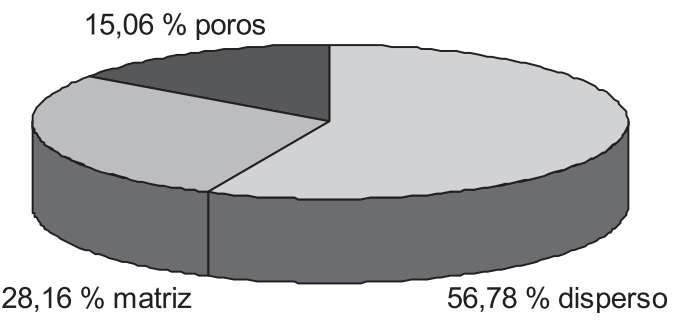

Figura 17.- Porcentaje de disperso, matriz y poros en monolíticos tipo R2

métricas de los poros de los refractarios.

Los porcentajes de poros, matriz y disperso se presentan en la Figura 17 y en la Figura 18 se puede observar que los poros disminuyen con aumento de temperatura.

En la Tabla IX se presentan las características geométricas de los poros dentro del refractario, como valores medios y sin las desviaciones estándar debido a la gran dispersión existente en el tamaño y forma de los poros. Se deduce una disminución en los tamaños y factores de forma de los poros con la temperatura, adquiriendo éstos formas más redondeadas.

\subsubsection{MUESTRAS TIPO R3}

En este refractario se ha obtenido el porcentaje de poros y de matriz y las características geométricas de los poros, cuyos resultados se muestran en la Figura 19 y Tabla X. El tamaño 

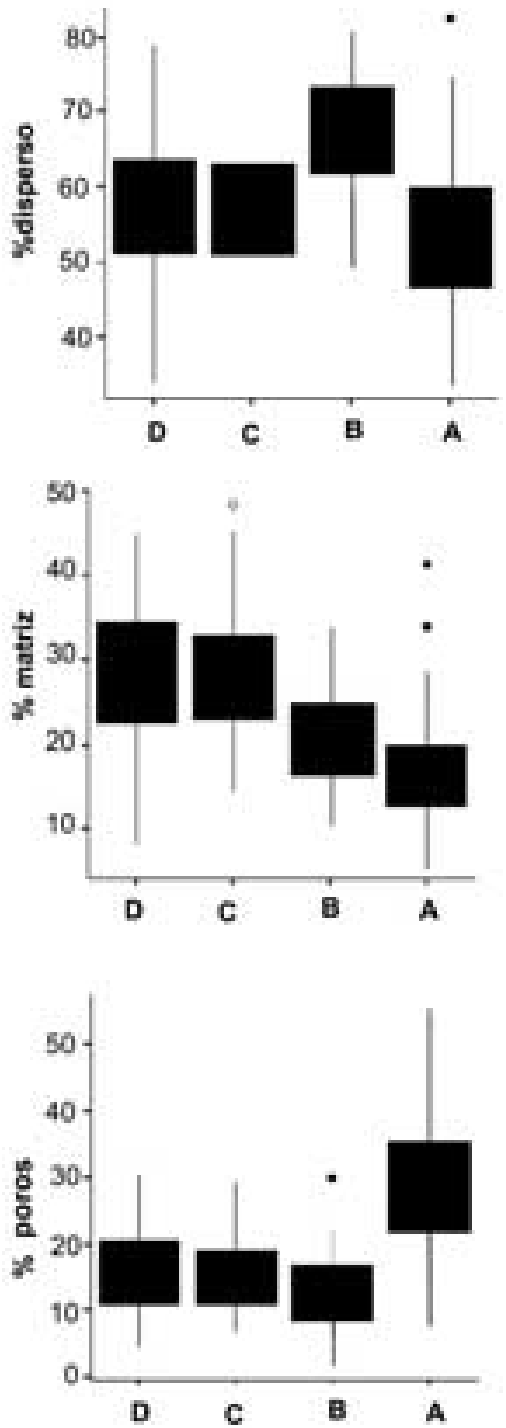

Figura 18.- Gráficos mostrando la evolución con los ciclos térmicos del disperso, matriz y poros en muestras de la composición química R2

TABla IX.- CARACTERísticas GeOMÉTRICAS DE LOS POROS EN LOS REFRACTARIOS R2(A),R2(B),R2(C) Y R2(D)

\begin{tabular}{|c|c|c|c|c|}
\hline Muestra & $\mathrm{L}$ & $\mathrm{B}$ & $\mathrm{R}$ & $\mathrm{N}^{\circ}$ \\
\hline R2(A) & 38,00 & 30,32 & 2,22 & 3360 \\
R2(B) & 26,12 & 13,59 & 1,77 & 3582 \\
R2(C) & 29,98 & 15,65 & 1,79 & 4059 \\
R2(D) & 30,44 & 15,71 & 1,97 & 3832 \\
\hline
\end{tabular}

TABla X.- CARACterísticas geOMÉtricas de los pOROS en el REFractaRIO R3

\begin{tabular}{|l|cccc|}
\cline { 2 - 5 } \multicolumn{1}{c|}{} & $\mathrm{L}$ & $\mathrm{B}$ & $\mathrm{R}$ & $\mathrm{N}^{\circ}$ \\
\hline Muestra R3 & 18,00 & 11,44 & 1,38 & 4778 \\
\hline
\end{tabular}

$16.82 \%$

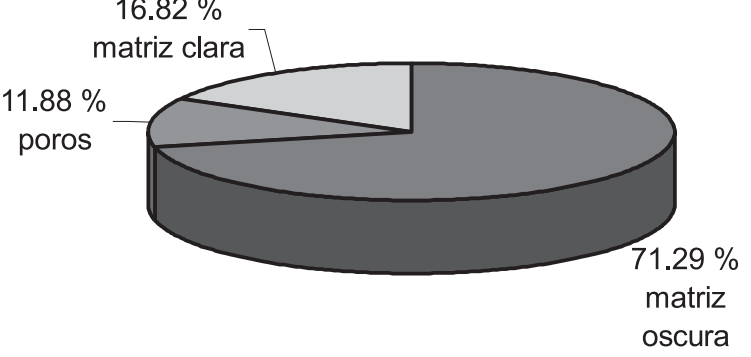

Figura 19.- Porcentaje de poros y matriz en la muestra R3

de los poros comprendido entre $0.01 \mathrm{~mm}^{2}$ y $20 \mu \mathrm{m}^{2}$ resulta pequeño comparado globalmente al de los otros refractarios estudiados en este trabajo. En cuanto a la forma se puede decir que, en general, son bastante redondeados, principalmente los de menor tamaño.

\section{CONCLUSIONES}

I) Con las técnicas de difracción de rayos $X$ (método de polvo cristalino), microsonda electrónica y microscopía óptica se han caracterizado mineralógicamente los refractarios monolíticos estudiados, operación fundamental para analizar la evolución de su estructura con los ciclos térmicos mediante el análisis con proceso de imágenes.

a) La difracción de rayos $X$ ha proporcionando la identificación de las fases mayoritarias presentes en los refractarios y ha puesto de manifiesto, además, en el refractario de alta alúmina y bajo contenido en cemento (R1) dos hechos importantes porque indican mayor resistencia de estos refractarios con temperatura elevada:

b) Crecimiento del corindón a partir de las fases mullíticas de la matriz con los ciclos térmicos.

c) Disminución en las intensidades de las reflexiones de las fases presentes con los ciclos térmicos.

2) Con los análisis de microsonda electrónica se ha podido conocer la composición de dichas fases minerales y su ubicación en el disperso y/o en la matriz de los mismos, imprescindible para el análisis textural con el proceso de imágenes.

- En el refractario R1 sin tratar y en el tratado con ciclos térmicos las fases minerales mayoritarias identificadas por difracción de rayos $X$ como corindón y moissanita forman parte del disperso y la matriz está compuesta por fases mullíticas en solución sólida.

- En los refractarios R2 la única fase mineral presente identificada y analizada, la periclasa, constituye el disperso.

- Por último, en el refractario R3 las fases mayoritarias identificadas y analizadas, corindón y fases mullíticas en solución sólida, no están diferenciadas como consecuencia de las características físico - químicas de las materias primas utilizadas en la sinterización previa a la cual ha estado sometida la muestra.

II) Con la caracterización textural mediante análisis de proceso de imágenes se ha podido:

a) Discriminar las fases minerales mayoritarias presentes en las muestras. 
- En los refractarios ricos en alúmina y con bajo contenido en cemento, caso de R1, la fase mayoritaria es el corindón; sin embargo, en R3 es una fase mullítica debido a que tiene un contenido más elevado en sílice.

- En los refractarios R2 cuyo componente básico es la magnesia y tienen un alto contenido en cemento la fase que compone el disperso es la periclasa.

b) Establecer que la porosidad disminuye con el número de ciclos térmicos (para una misma temperatura) y con aumento de la temperatura (para el mismo número de ciclos), al mismo tiempo que los poros se hacen más redondeados. Estos resultados eran de esperar ya que termodinámicamente la energía libre superficial tiende a minimizarse. Por otra parte, las estructuras resultantes son más resistentes a la fatiga térmica que las de partida.

III) El análisis con proceso de imágenes en el caso de este tipo de refractarios proporciona información (cuantificación, forma, tamaño) no sólo de los poros sino también del disperso y de la distribución de los poros en los distintos constituyentes del material, marcando diferencias frente al porosímetro, técnica rutinaria muy utilizada para obtener de forma rápida el tamaño (entre 100 y $0.001 \mu \mathrm{m}$ ). Por otra parte, el análisis con proceso de imágenes no es una técnica destructiva como el porosímetro y se pueden procesar imágenes con una resolución superior, en función de la óptica utilizada.

\section{AGRADECIMIENTOS}

Este trabajo ha sido realizado con cargo al proyecto MAT2000-1715 del MCYT.

\section{BIBLIOGRAFÍA}

1. S. Banerjee «Monolithic Refractories. A Compresive Handbook». The American Ceramic Society. World Scientific (1998)

2. L.F. Verdeja, R. González \& A. Ordoñez «Using FEM to determine temperature distribution in a blast furnace crucible ». J. Metals, Vol. 52, No. 2, 7477 (2000)

3. JCPDS-International Centre for Difraction Data. Version $1.13 \mathrm{c}$ «Pdf-2 Data base (Sets 1-46) » (1996)

4. G. MacZura, J.E. Kopanda, F.J. Rohr, \& P. T. Rothenbuehler «Calcium Aluminate Cements for Emerging Castable Tecnology»; Adv. Cer. 13, pag. 85-301 (1985)

5. C. Marcos y D. Moreiras «Obtención de secciones pulidas en muestras granuladas utilizadas en la toma de medidas de reflectancia». Trabajos de Geología, Univ. de Oviedo, 14 (1984)

6. S. Cornelius Hurlbut, JR. Cornelis Klein «Manual de mineralogía de Dana». Ed. Reverté (3ㄹed.) (1987)

7. M.P. Jones «Automatic Image Analysis». In J. Zussman (ed) Physical Methods in Determinative Mineralogy. Academic Press (1977)

8. Paquete Estadístico SPSS (versión 9.0) bajo Windows (1989-1999)

9. W. D. Wayne «Biostatistics. A foundation for analysis in the health sciencies». John Wiley and Sons. Inc. (1995)

10. S. Seltveit, G.Dhupia and W. Kronert «Microstructural Aspects of Microsilice-Blended High Alumina Castables», Cer. Eng. Sc. Proc., 7, № 1-2, 243-260 (1986)

Recibido: 16.11 .00

Aceptado: 11.02 .02

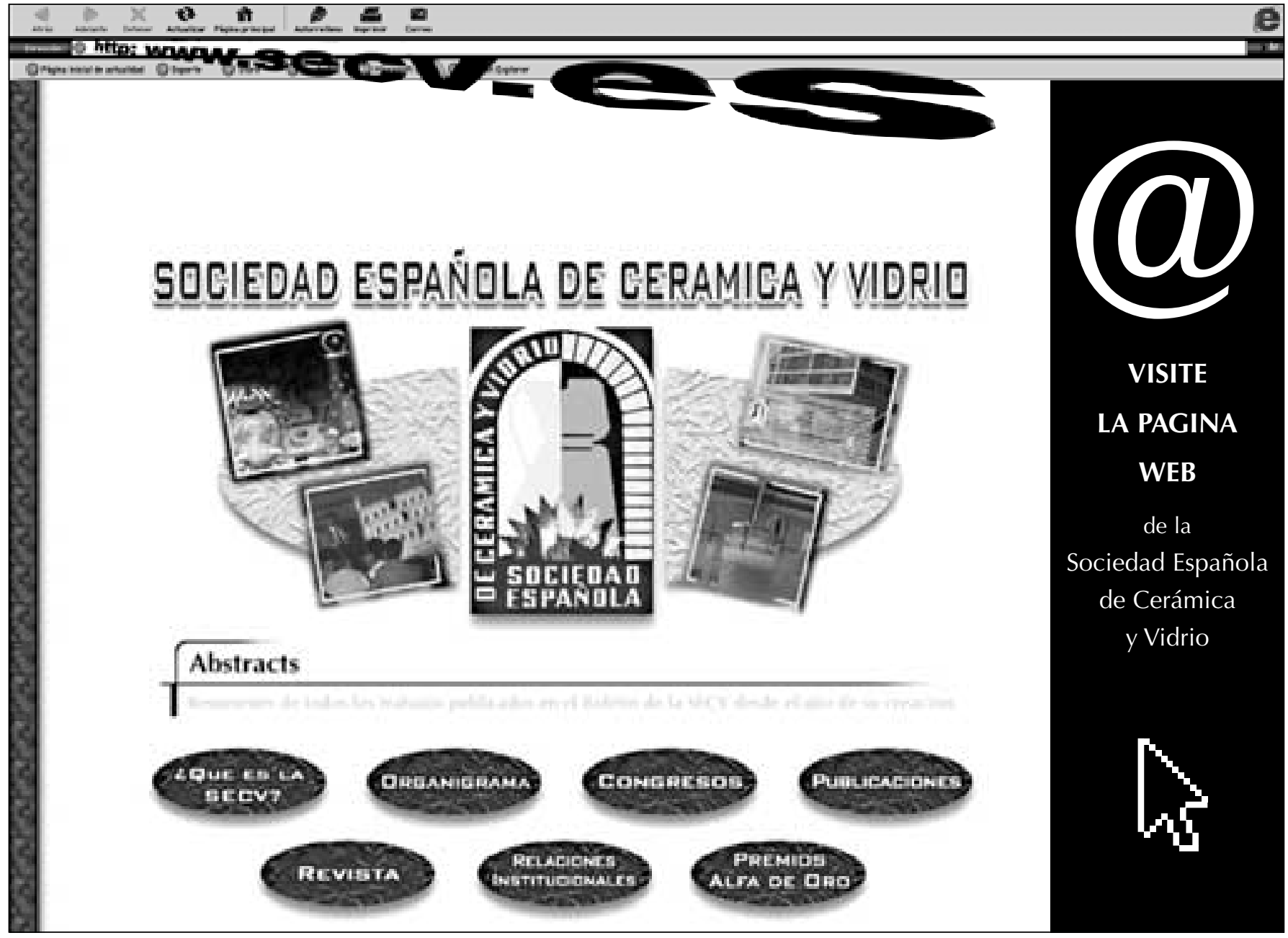

